PPARa and PPAR $i$ are co-expressed, functional and show positive interactions in the rat urinary bladder urothelium

Brunner, Nils; Egerod, Frederikke N S Lihme; Svendsen, Jette E. ; Oleksiewicza, Martin B.

Published in:

Journal of Applied Toxicology

DOI:

10.1002/jat.1481

Publication date:

2009

Document version

Early version, also known as pre-print

Citation for published version (APA):

Brunner, N., Egerod, F. N. S. L., Svendsen, J. E., \& Oleksiewicza, M. B. (2009). PPARa and PPAR $i$ are coexpressed, functional and show positive interactions in the rat urinary bladder urothelium. Journal of Applied Toxicology, 151-162. https://doi.org/10.1002/jat.1481 


\title{
PPAR $\alpha$ and PPAR $\gamma$ are co-expressed, functional and show positive interactions in the rat urinary bladder urothelium
}

\author{
Frederikke Lihme Egerod, ${ }^{a, b}$ Nils Brünner, ${ }^{b}$ Jette E. Svendsen $^{a}$ and Martin \\ B. Oleksiewicz ${ }^{\mathrm{a} *}$
}

\begin{abstract}
Some dual-acting PPAR $\alpha+\gamma$ agonists cause cancer in the rat urinary bladder, in some cases overrepresented in males, by a mechanism suggested to involve chronic stimulation of PPAR $\alpha$ and PPAR $\gamma$, i.e. exaggerated pharmacology. By western blotting, we found that the rat urinary bladder urothelium expressed PPAR $\alpha$ at higher levels than the liver and heart, and comparable to kidney. Urothelial expression of PPAR $\gamma$ was above that of fat, heart, skeletal muscle and kidney. Male rats exhibited a higher PPAR $\alpha$ /PPAR $\gamma$ expression balance in the bladder urothelium than did female rats. Rats were treated by gastric gavage with rosiglitazone (PPAR $\gamma$ agonist), fenofibrate (PPAR $\alpha$ agonist) or a combination of rosiglitazone and fenofibrate for 7 days. In the urothelium, the transcription factor Egr-1 was induced to significantly higher levels in rats coadministered rosiglitazone and fenofibrate than in rats administered either rosiglitazone or fenofibrate alone. Egr-1 was also induced in the heart and liver of rats treated with fenofibrate, but a positive interaction between rosiglitazone and fenofibrate with regards to Egr-1 induction was only seen in the urothelium. Thus, in the rat urinary bladder urothelium, PPAR $\alpha$ and PPAR $\gamma$ were expressed at high levels, were functional and exhibited positive interactions. Interestingly, fenofibrate induced the peroxisome membrane protein PMP70 not only in liver, but also in the bladder urothelium, opening the possibility that oxidative stress may contribute to rat urothelial carcinogenesis by dual-acting PPAR $\alpha+\gamma$ agonists. Copyright $\odot 2009$ John Wiley \& Sons, Ltd.
\end{abstract}

Keywords: rat urinary bladder cancer; molecular toxicology; preclinical carcinogenicity safety assessment; urothelium; PMP70; Egr-1

\section{INTRODUCTION}

PPARs (peroxisome proliferator-activated receptors) belong to the nuclear hormone receptor family of transcription factors (Michalik et al., 2006). Three PPARs, produced by three different genes, have been identified: PPAR $\alpha, \operatorname{PPAR} \beta / \delta$ and PPAR $\gamma$ (Dreyer et al., 1992). PPAR $\alpha$ and PPAR $\gamma$ exhibit largely non-overlapping expression patterns: PPAR $\alpha$ expression is highest in liver, heart, kidney and skeletal muscle (Braissant et al., 1996; Guan et al., 1997; Michalik et al., 2006). PPAR $\gamma$ expression is highest in adipose tissue, colon, leucocytes and retina (Braissant et al., 1996; Guan et al., 1997; Michalik et al., 2006). PPAR $\delta$, also known as PPAR $\beta$, is more ubiquitously expressed (Braissant et al., 1996; Escher et al., 2001; Guan et al., 1997; Michalik et al., 2006).

Because of their significance in metabolic regulation, PPARs are important drug targets in, for example, type II diabetes and metabolic syndrome (Berger et al., 2005). Selective PPAR $\alpha$ agonists (fibrates) normalize blood lipids, and selective PPAR $\gamma$ agonists (thiazolidinediones) are used as insulin sensitizers (Michalik et al., 2006). Because of the beneficial effects of selective PPAR $\alpha$ and PPAR $\gamma$ agonists, dual-acting PPAR $\alpha+\gamma$ agonists have also been developed, which combine agonist activity for both the PPAR $\alpha$ and PPAR $\gamma$ (Brand et al., 2003; Fiévet et al., 2006; ReifelMiller et al., 2005). However, the preclinical development of dualacting PPAR $\alpha+\gamma$ agonists has been made difficult by carcinogenic effects in rodents, in particular affecting the epithelial lining of the urinary bladder (the urothelium) (Oleksiewicz et al., 2008).

For some dual-acting PPAR agonists, the rat urothelial carcinogenicity has been suggested to be receptor-mediated, i.e. due to exaggerated pharmacology (Oleksiewicz et al., 2008). The urothelium is relatively unique in co-expressing PPAR $\alpha$ and PPAR $\gamma$ (Chopra et al., 2008; Guan et al., 1997). However, PPAR $\alpha$ and PPAR $\gamma$ expression in bladder urothelium at the protein level has never been examined by quantitative methods; i.e. it is essentially unknown whether PPAR $\alpha$ and PPAR $\gamma$ co-expression in the urothelium is of sufficient magnitude for functionality including involvement in carcinogenicity to be plausible. Furthermore, because selective PPAR $\alpha$ and PPAR $\gamma$ agonists appear to exhibit a lower propensity for causing bladder cancer in rats than do dualacting PPAR $\alpha+\gamma$ agonists (Oleksiewicz et al., 2008), and because

*Correspondence to: M. B. Oleksiewicz, Intercell AG, Molecular Microbiology, Campus Vienna Biocenter 3, OG 04.034, 1030 Vienna, Austria.

Email: moleksiewicz@intercell.com

${ }^{a}$ Molecular Toxicology, Novo Nordisk A/S, Novo Nordisk Park, DK-2760 Maalov, Denmark

${ }^{b}$ The Institute of Veterinary Patobiology, Faculty of Life Sciences, University of Copenhagen, Ridebanevej 9, DK-1870 Frederiksberg, Denmark 
Table 1. Dose groups, rat experiment

\begin{tabular}{|c|c|c|c|}
\hline Test group & Group size & Dose level $\left(\mathrm{mg} \mathrm{kg}^{-1}\right.$ day $\left.^{-1}\right)$ & PPAR agonism \\
\hline 1 Vehicle & 10 & n.a. & n.a. \\
\hline 2 Rosiglitazone & 5 & 8 & $\gamma$ \\
\hline 3 Rosiglitazone & 5 & 20 & $\gamma$ \\
\hline 4 Fenofibrate & 5 & 50 & $\alpha$ \\
\hline 5 Fenofibrate & 5 & 200 & $\alpha$ \\
\hline 6 Rosiglitazone + fenofibrate & 5 & $8+200$ & Dual $(\alpha / \gamma)$ \\
\hline 7 Rosiglitazone + fenofibrate & 5 & $20+200$ & Dual $(\alpha / \gamma)$ \\
\hline 8 Rosiglitazone + fenofibrate & 5 & $20+50$ & Dual $(\alpha / \gamma)$ \\
\hline
\end{tabular}

the selective PPAR $\gamma$ agonist rosiglitazone promotes rather than initiates bladder cancer in rats (Lubet et al., 2008), it appears plausible that the bladder carcinogenic effect of dual-acting $\operatorname{PPAR} \alpha+\gamma$ agonists might involve crosstalk between PPAR $\alpha$ and PPAR $\gamma$ signalling in the urothelium (Oleksiewicz et al., 2008). It is currently unknown whether functional interactions occur between PPAR $\alpha$ and PPAR $\gamma$ in cells coexpressing these two nuclear receptors. To explore these issues, we have in this study compared PPAR $\alpha$ and PPAR $\gamma$ expression levels between rat bladder urothelium, and a panel of rat tissue where carcinogenicity by dual-acting PPAR $\alpha+\gamma$ agonists is less common or does not occur (kidney cortex, kidney medulla, kidney papilla, liver, heart, white fat and red skeletal muscle). PPAR $\alpha$ and PPAR $\gamma$ functionality and crosstalk were tested by treating rats with specific PPAR $\alpha$ and PPAR $\gamma$ agonists, alone or in combination. The main endpoint was expression of the transcription factor Egr-1, which was previously suggested as a candidate biomarker for the carcinogenic effect of dual-acting PPAR agonists in the rat bladder urothelium (Oleksiewicz et al., 2008).

\section{MATERIALS AND METHODS}

\section{PPAR $\alpha$ and PPAR $\gamma$ Agonist Formulations}

Fenofibrate (PPAR $\alpha$ agonist, Sigma-Aldrich) and rosiglitazone (PPAR $\gamma$ agonist, kindly supplied by Per Sauerberg and Erik Max Wulff, Novo Nordisk A/S) dry substances were used to make separate suspensions of fenofibrate $\left(40 \mathrm{mg} \mathrm{ml}^{-1}\right)$ and rosiglitazone $\left(1.6 \mathrm{mg} \mathrm{m}^{-1}\right)$ in a vehicle consisting of $0.2 \% \mathrm{w} / \mathrm{w}$ sodium carboxymethyl cellulose, $0.4 \% \mathrm{w} / \mathrm{w}$ Tween 80 and $0.8 \% \mathrm{w} / \mathrm{w}$ sodium chloride, by sonication and vigorous magnet stirring (concentrations and doses refer to free acid/base).

The suspensions were stored protected from light at $2-8{ }^{\circ} \mathrm{C}$ and used within 7 days. Before dosing the suspensions were magnet stirred vigorously, for at least $10 \mathrm{~min}$, and maintained on the stirrer while animals were dosed. A daily record of the weight of each formulation before and after dosing was maintained, to verify that the dosages had been administered correctly.

\section{Oral Treatment of Rats with PPAR $\alpha$ and PPAR $\gamma$ Agonists}

Male Sprague-Dawley rats, 6 weeks old, were obtained from Taconic Europe (Denmark), and acclimatized for 11 days before the start of the studies. The rats were housed on a 12:12 h lightdark cycle, in transparent type IV macrolone cages (floor area
$1800 \mathrm{~cm}^{2}$, height $31 \mathrm{~cm}$ ) with two to four animals in each cage. The cages were bedded with aspen wood shavings, and contained wooden blocks (Finn Tapei Oy, Kortteinen, Finland), paper strand material (Enviro-Dri ${ }^{\circledR}$ nesting, Lillico, Betchworth, UK) and plastic shelters (Bachvent, Søborg, Denmark). Food pellets (complete pelleted rodent diet, Altromin 1320, order 1324, Brogården, Hørsholm, Denmark) and water (automated water system) were available ad libitum. Twice weekly the animals were offered a small amount of cereal grain and maize. The animal room temperature was maintained at $18-24^{\circ} \mathrm{C}$, the relative air humidity at 30-70\%, and the air change at 8-15 times $\mathrm{h}^{-1}$.

Animals were randomized and allocated to one of eight test groups: a negative control (vehicle) group of 10 animals, and seven treatment groups, each of five animals, comprising different dosages of specific PPAR $\alpha$ agonist (fenofibrate), specific $\operatorname{PPAR} \gamma$ agononist (rosiglitazone) or rosiglitazone + fenofibrate combination treatments (Table 1); i.e. a total of 45 rats were used for the experiment (Table 1).

Animals were dosed once daily by oral gavage, for 7 days (i.e. the animals received seven doses). The gastric gavage volume was the same for all test groups $\left(5 \mathrm{ml} \mathrm{kg}^{-1}\right)$, except for the rosiglitazone + fenofibrate group $\left(10 \mathrm{ml} \mathrm{kg}^{-1}\right)$. The animals were weighed at the start of the experiment, and on the day of necropsy, which was done $4 \mathrm{~h}$ after the last dosing.

\section{Comparison of PPAR $\alpha$ and PPAR $\gamma$ Expression Between Bladder Urothelium and Kidney Cortex, Medulla and Papilla in Male and Female Rats}

Five female and five male Sprague-Dawley rats, 6 weeks old, were obtained from Taconic Europe (Denmark), and acclimatized for 7 days. The rats were housed as described above. Lysates of the bladder urothelium, kidney cortex, kidney medulla and kidney papilla for western blotting were prepared as described below.

\section{In Situ Lysis of the Bladder Urothelium for Western Blotting}

After 7 days of treatment, animals were anesthetized with isoflurane- $\mathrm{N}_{2} \mathrm{O}\left(0.7 \mathrm{I} \mathrm{min}^{-1}\right)-\mathrm{O}_{2}\left(0.31 \mathrm{~min}^{-1}\right)$ with $5 \%$ isoflurane to deep anesthesia, thereafter reduced to $2 \%$ to maintain stable anesthesia. With animals in deep anesthesia, the bladder urothelium was lysed in situ by injecting $0.5 \mathrm{ml}$ of a strongly denaturing guanidine isothiocyanate solution into the bladder lumen, as described previously (Egerod et al., 2005). The anesthetized animals were then euthanized by exsanguination. 


\section{Lysis of Tissue Samples for Western Blotting:}

Heart and liver were removed immediately from the euthanized animals, and the weight of the organs was recorded. The apex of the heart (approximately $3 \times 3 \times 3 \mathrm{~mm}$ ) and a $3 \times 3 \times 3 \mathrm{~mm}$ piece of the left liver lobe were homogenized in $1500 \mu$ l polypropylene tubes (Sample Grinding kit, Amersham Biosciences), in approximately $1 \mathrm{ml}$ of a denaturing and reducing loading buffer for SDSPAGE, consisting of $2 \times$ LDS sample buffer (Invitrogen, California, USA), $2 \times$ reducing agent (Invitrogen), 1:200 vol. protease inhibitors (cocktail III, Calbiochem, Damstadt, Germany), 1:100 vol. phosphatase inhibitors (cocktail II, Calbiochem) and 10 mm EDTA. The LDS buffer was proprietary, but contained bromphenol blue tracking dye, density agent and high detergent levels, probably SDS.

Mesenterial white fat from the abdomen and the superficial (red) part of the gastrocnemius muscle from the right hind leg were homogenized likewise, in denaturing and reducing loading buffer for SDS-PAGE.

Approximately $3 \mathrm{~mm}$-thick slices were prepared of the right kidney by two parallel cuts from pole to pole, along the large curvature. From these slices, samples of the cortex and medulla, as well as the whole papilla, were manually dissected, and homogenized in denaturing and reducing loading buffer for SDS-PAGE.

Tissue lysates were stored at $-20^{\circ} \mathrm{C}$.

\section{Antibodies}

Alpha-tubulin mouse monoclonal antibody (Sigma, Missouri, USA, catalog number T 6199) raised against purified chick brain tubulin was used at a dilution of $1: 6000$.

Beta-actin mouse monoclonal antibody (Abcam, Cambridge, UK, catalog number ab6276) raised against a synthetic peptide correponding to amino acids 1-14 of Xenopus laevis Actin was used at a dilution of $1: 80000$.

Glyceraldehyde 3-phosphate dehydrogenase (GAPDH) mouse monoclonal antibody (Abcam, Cambridge, UK, catalog number ab8245) raised against rabbit muscle GAPDH was used at a dilution of $1: 100000$.

Egr-1 rabbit affinity purified polyclonal immunoglobulin (Santa Cruz Biotechnology, California, USA, catalog number C-19, sc-189) raised against a peptide mapping at the carboxy terminus of human Egr-1 was used at a dilution of 1:1000.

PMP70 (peroxisomal membrane marker) rabbit polyclonal immunoglobulin (Abcam, Cambridge, UK, catalog number ab3421), raised against a synthetic peptide corresponding to amino acid residues 644-659 from rat PMP70 was used at a dilution of $1: 5000$.

PPAR $\alpha$ rabbit affinity purified anti-peptide immunoglobulin (Affinity Bioreagents, catalog number PA1-822) raised against a synthetic peptide corresponding to amino acid residues 1-18 from murine PPAR $\alpha$ was used at a dilution of $1: 1000$.

PPAR $\gamma$ rabbit monoclonal antibody (Cell Signaling Technology, California, USA, catalog number 2443), raised against a synthetic peptide derived from the sequence around His494 of human PPAR $\gamma$ was used at a dilution of 1:1000.

HRP-conjugated goat anti-mouse IgG (Cell Signaling Technology, catalog number 7076) was used at a dilution of $1: 10000$. HRP-conjugated horse anti-rabbit IgG (Cell Signaling Technology, catalog number 7074) was used at a dilution of $1: 10000$.

\section{Western Blotting}

The urothelial lysates in guanidine isothiocyanate were dialyzed against $8 \mathrm{~m}$ urea, $20 \mathrm{~mm}$ Tris (pH 8.0), 5 mM EDTA, 1:200 vol. protease inhibitors (cocktail III, Calbiochem, Damstadt, Germany, catalog number 539134), 1:100 vol. phosphatase inhibitors (cocktail II, Calbiochem, catalog number 524625), as previously described (Egerod et al., 2005).

Western blotting is in our opinion the current gold standard for detection and quantitation of Egr-1 protein in rat organ lysates, and probably the only technique where comparison of Egr-1 protein levels between different rat organs can credibly be attempted, as done in this study. Unfortunately, because of the size of the gradient SDS-PAGE gels employed in our study (17 wells), and the requirement that for most precise quantitation, all samples between which comparison is done should be on a single gel (samples cannot be distributed on individual gels due to e.g. variability in protein transfer), it was not possible in this study to analyze individual samples. Instead, samples were pooled and quantitation based on three to five independent western blot experiments (three to five independent technical assay replicates), as described below and in the figure legends. Analyzing pooled samples is expected to be equivalent to analyzing samples from individual animals and taking an average of the individual animals, and this was supported by a study where samples from individual animals were examined by western blotting as well as immunohistochemistry (Egerod et al., submitted).

For the rat experiment comprising oral treatment with PPAR agonists for 7 days, urothelial lysates were pooled for each treatment group, adjusting the volume used from each animal to provide the same total protein contribution to the pool, and finally adjusting the pool volumes to obtain identical protein concentrations in all pools $\left(1.3 \mathrm{mg} \mathrm{ml}^{-1}\right)$. Thus, one vehicle pool comprising 10 animals and seven treatment pools each comprising five animals were made (Table 1). The heart and liver lysates were likewise pooled into eight heart and eight liver lysate pools. Thus, the whole animal experiment, consisting of 45 animals, was reduced to eight urothelial lysate pools, eight liver lysate pools, and eight heart lysate pools. In preliminary experiments, the protein content in all $3 \times 8=24$ organ pools was comprehensively examined and compared by a combination of methods: NanoOrange staining combined with dilution to reduce detergent levels (NanoOrange ${ }^{\circledR}$ Protein Quantification kit, Molecular Probes, Oregon, USA), SDS-PAGE and Coomassie staining (see below), amido black dot blotting (see below) and western blotting with a cocktail of $\alpha$-Tubulin, $\beta$-Actin and GAPDH antibodies.

For the comparison of PPAR $\alpha$ and PPAR $\gamma$ expression between bladder urothelium and kidney cortex, medulla and papilla in male and female rats, urothelial lysate, kidney papilla lysate, kidney medulla lysate and kidney cortex lysate were pooled for the five males and five females; i.e. four lysate pools were made from males and four lysate pools were made from females. Pools were made and protein content between the eight lysate pools was compared as described above.

Fully denaturing and reducing SDS-PAGE of lysate pools on precast $4-12 \%$ gradient gels, electrotransfer of proteins to $0.45 \mu \mathrm{m}$ PVDF membranes and western blotting of PVDF membranes was done as previously described (Egerod et al., 2005).

For quantitation of PPAR agonist-induced Egr-1 expression, five replicate western blots were done of the same lysates. For 
quantitation of PPAR and endogenous Egr-1 expression, three replicate western blots were done of the same lysates.

Western blots were developed using $\mathrm{ECL}^{\text {Advance }}$ chemiluminescent substrate (GE Healthcare, New Jersy, USA) and a LAS3000 CCD camera (Fujifilm). Exposures were done in the quantitative (non-saturated) range of the CCD camera, as recommended by the manufacturer. Quantitative image analysis was done with MultiGauge software (v2.3, Fujifilm) (Egerod et al., 2005).

Finally, membranes were stripped (Restore Western blot stripping buffer, Pierce) for $1 \mathrm{~h}$ at $37^{\circ} \mathrm{C}$ (Pierce) and reprobed with a load control cocktail of three antibodies ( $\alpha$-tubulin, $\beta$-actin and GAPDH).

\section{Coomassie Staining}

SDS-PAGE of tissue lysate pools was done on precast $4-12 \%$ gradient gels, according to the manufacturer's instructions (NuPAGE ${ }^{\mathrm{TM}}$ gels, Invitrogen, California, USA). The gels were incubated for $20 \mathrm{~min}$ in $50 \%$ methanol, $7 \%$ acetic acid, then washed for $3 \times$ 5 min in water, stained with GelCode Coomassie blue (Pierce) for $2 \mathrm{~h}$ and destained in water for $1 \mathrm{~h}$ before scanning on a standard Hewlett Packard flatbed scanner (HP Scanjet 7400C).

\section{Protein Quantitation by Amido Black Nitrocellulose Dot Blot Assay}

Determination of total protein concentration in urothelial lysates (in guanidine isothiocyanate, GuSCN) and in liver, heart, fat and muscle lysates (in denaturing and reducing loading buffer for SDS-PAGE) was performed using amido black (DieckmannSchuppert and Schnittler, 1997; Henkel and Bieger, 1994). Protein samples were applied as $2 \mu \mathrm{l}$ spots onto nitrocellulose filters (Hybond-C Extra, Amersham). Standards of known protein concentration were prepared by serially diluting bovine serum albumin in either GuSCN lysis buffer or denaturing and reducing loading buffer for SDS-PAGE, and likewise applied to nitrocellulose filters.

The nitrocellulose filters were dried for $15 \mathrm{~min}$ at room temperature and stained in $0.1 \%$ amido black $10 \mathrm{~B}(\mathrm{w} / \mathrm{v}), 45 \%$ metha- nol, $45 \%$ water and $10 \%$ glacial acetic acid for $3 \mathrm{~min}$. Stained filters were washed twice in water and twice in $90 \%$ methanol, $2 \%$ glacial acetic acid and $8 \%$ water, for 3 min each time and finally in water for $5 \mathrm{~min}$. Areas of $1 \mathrm{~cm}^{2}$, each containing one protein spot, were cut from the nitrocellulose filters, transferred to Eppendorf tubes, and protein-bound dye was eluted in $0.5 \mathrm{ml}$ $50 \% 50 \mathrm{~mm} \mathrm{NaOH}-0.1 \mathrm{~mm}$ EDTA, 50\% EtOH, under shaking for $30 \mathrm{~min}$ at room temperature. Eluates were transferred to clear 96 well plates ( $150 \mathrm{ul} /$ well), and absorbance was measured at $672 \mathrm{~nm}$.

The method was validated by linear regression lines obtained from serial dilutions of BSA, spanning $5 \mathrm{mg} \mathrm{ml}^{-1}$ through $0.19 \mathrm{mg} \mathrm{ml}^{-1}$, in GuSCN lysis buffer and in denaturing and reducing loading buffer for SDS-PAGE sample buffer. BSA diluted in these two buffers produced linear standard curves $\left(r^{2}=0.999\right)$ that were parallel. Thus, the amido black method was highly tolerant to the type of buffer the protein was diluted in, and allowed comparison of protein concentration between rat tissue lysates prepared in SDS-PAGE sample buffer and guanidine isothiocyanate solution, as expected (Dieckmann-Schuppert and Schnittler, 1997; Henkel and Bieger, 1994).

\section{RESULTS}

\section{Effect of PPAR $\alpha$ and PPAR $\gamma$ Agonists on Organ and Body Weights}

Body weights were obtained at the first and last days of dosing. As expected for young rats, all groups exhibited increases in body weight during the experiment, but no significant differences were seen in bodyweight gains between vehicle and treated groups (not shown).

Neither rosiglitazone nor fenofibrate nor the combination treatments significantly affected heart weights, albeit small, nonsignificant increases in heart weights were seen in both rosiglitazone dose groups, and the low-dose fenofibrate group (not shown). Likewise, rosiglitazone did not affect liver weights (Fig. 1). In contrast, animals treated with the PPAR $\alpha$ agonist fenofibrate, either alone or in combination with rosiglitazone, exhib-
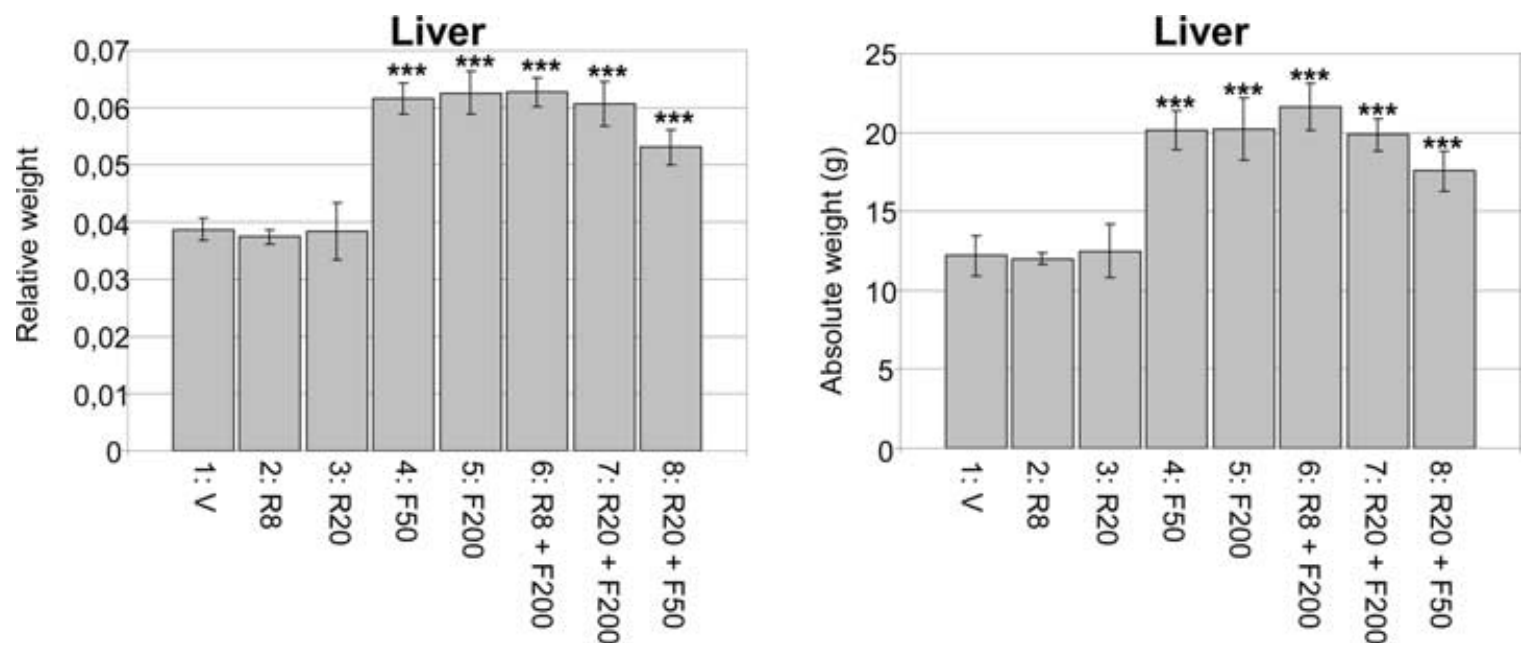

Figure 1. Liver weights. $x$-Axis, treatment groups: 1 , vehicle; 2 , rosiglitazone ( $8 \mathrm{mg} \mathrm{kg}^{-1}$ per day); 3 , rosiglitazone $\left(20 \mathrm{mg} \mathrm{kg}^{-1}\right.$ per day); 4 , fenofibrate $\left(50 \mathrm{mg} \mathrm{kg}^{-1}\right.$ per day); 5 , fenofibrate $\left(200 \mathrm{mg} \mathrm{kg}^{-1}\right.$ per day); 6 , rosiglitazone + fenofibrate $\left(8+200 \mathrm{mg} \mathrm{kg}^{-1}\right.$ per day); 7 , rosiglitazone + fenofibrate $(20+$ $200 \mathrm{mg} \mathrm{kg}^{-1}$ per day); 8 , rosiglitazone + fenofibrate $\left(20+50 \mathrm{mg} \mathrm{kg}^{-1}\right.$ per day). Left bar diagram, relative liver weight (liver weight/bodyweight ratio). Right bar diagram, absolute liver weight. Both graphs show group means ( $n=10$ rats for vehicle group and $n=5$ rats for treatment groups), error bars, $1 \mathrm{SD}$. ${ }^{* * *} P<0.001$, compared with vehicle, one-way ANOVA with Newman-Keuls multiple-comparison post test. 
ited increased liver weights compared with the vehicle group (Fig. 1, see also discussion). Maximal increase in relative liver weight was seen with $50 \mathrm{mg} \mathrm{kg}^{-1}$ fenofibrate, and liver weights were not further increased in animals receiving $200 \mathrm{mg} \mathrm{kg}^{-1}$ fenofibrate. Finally, coadministration of rosiglitazone appeared to counteract the fenofibrate-induced increase in liver weights (Fig. 1, compare the $50 \mathrm{mg} \mathrm{kg}^{-1}$ fenofibrate and $50 \mathrm{mg} \mathrm{kg}^{-1}$ fenofibrate $+20 \mathrm{mg} \mathrm{kg}^{-1}$ rosiglitazone groups, $P=0.0317$ and 0.0079 for absolute and relative liver weights, respectively, MannWhitney test).

\section{Urinary Bladder Urothelium Coexpresses PPAR $\alpha$ and PPAR $\gamma$, at Levels above those Found in Liver, Heart, Fat and Skeletal Muscle}

Lysates of bladder urothelium, liver, heart, fat and muscle were examined for PPAR $\alpha$ and PPAR $\gamma$ expression by western blotting (Fig. 2A). Comparison of PPAR expression levels between tissues was complicated by several factors. First, some tissue such as fat and skeletal muscle yielded low protein levels, estimated by Coomassie staining (Fig. 2B). To improve the sensitivity of PPAR detection, we loaded maximal amount of protein for each tissue type. Consequently, there was up to a 4-fold difference in total protein load applied to the SDS-PAGE gel between tissues (Fig. $2 \mathrm{~B}$ and $\mathrm{C}$ ). Second, housekeeping proteins commonly used for normalization, such as $\alpha$-tubulin, $\beta$-actin and GAPDH, exhibited tissue-specific expression (Fig. 2A, bottom panel). Therefore, $\alpha$-tubulin, $\beta$-actin and GAPDH were primarily used to verify equal loading for the same type of tissue (Fig.e 2A, bottom panel, compare for example three lanes with bladder lysate). Finally, tissue lysates were prepared in sample buffers containing high detergent levels. Therefore, protein loading was determined by an amido black dot blot assay which is tolerant to detergent and Coomassie-stained SDS-PAGE gels were used as extra control (Fig. 2B and C).

Highest PPAR $\alpha$ levels were detected in bladder urothelium, liver, kidney and heart, while fat and muscle did not exhibit PPAR $\alpha$ bands (Figs 2A and 3A, top panel, angled arrowheads in Fig. 2A). In the liver as well as kidney, two bands were seen with the PPAR $\alpha$ antibody (Figs $2 \mathrm{~A}$ and 3A, top panels). The affinitypurified anti-PPAR $\alpha$ antibody, directed against the 18 first $\mathrm{N}$-terminal amino acids of PPAR $\alpha$, is known to produce a doublet band (abcam technical information). Also, others have reported doublet bands from rat liver with antibodies against the first 101 $\mathrm{N}$-terminal amino acids of PPAR $\alpha$ (Lemberger et al., 1996). In bladder urothelium and heart, only one band was seen with the $\operatorname{PPAR} \alpha$ antibody, which comigrated with the quicker-migrating band in liver and kidney (Figs 2A and 3A, top panels). Therefore, the quicker-migrating, bottom band was used for PPAR $\alpha$ expression comparison between tissue (Fig. 2A, top panel, angled arrows). It is possible that the slower-migrating band represented, for example, phosphorylation of PPAR $\alpha$ (Passilly et al., 1999; Shalev et al., 1996), i.e. this PPAR $\alpha$ quantitation strategy might have underestimated PPAR $\alpha$ expression in the liver and kidney by approximately 2-fold. Highest PPAR $\gamma$ levels were detected in bladder urothelium, heart, fat and muscle, while the liver did not exhibit a PPAR $\gamma$ band (Fig. 2A, middle panel, angled arrowheads).

For any given tissue type, PPAR $\alpha$ and PPAR $\gamma$ levels differed minimally between vehicle-treated animals and animals

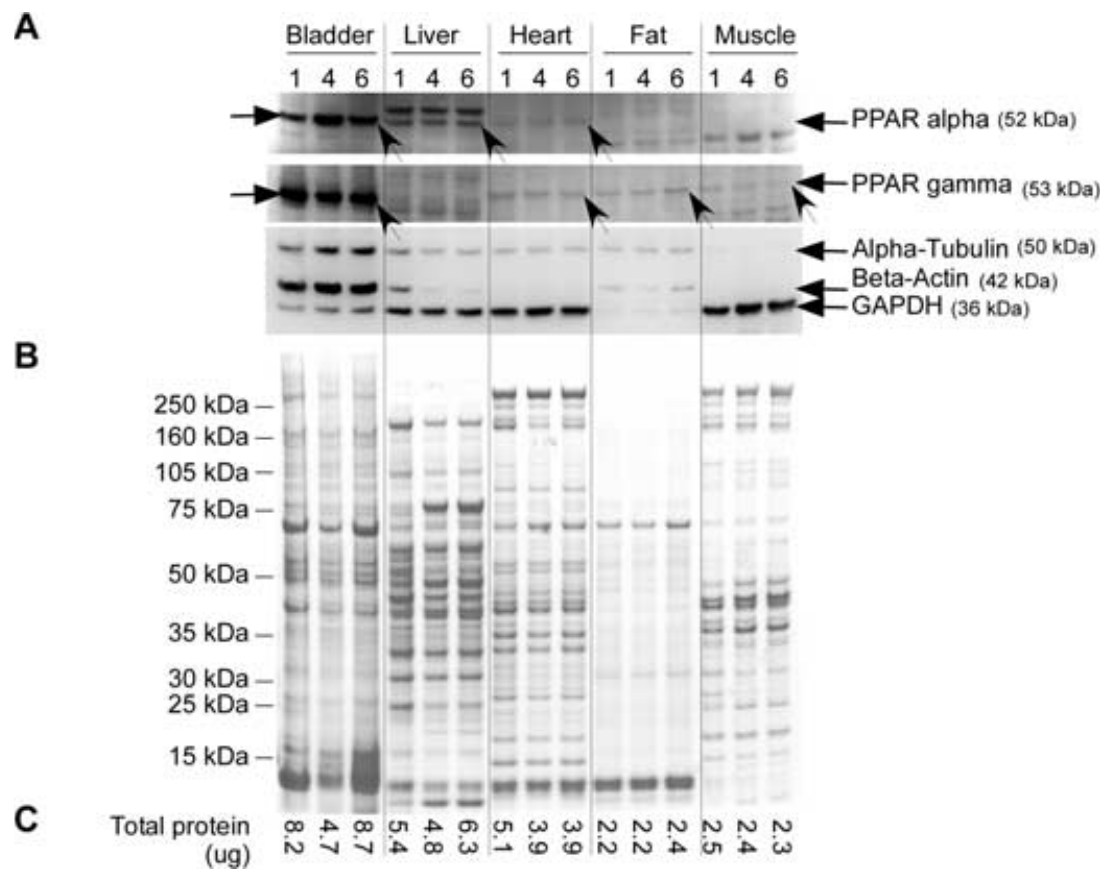

Figure 2. PPAR $\alpha$ and PPAR $\gamma$ expression in rat bladder urothelium, liver, heart, fat and muscle. Numbers above lanes: treatment groups. 1, Vehicle; 4,

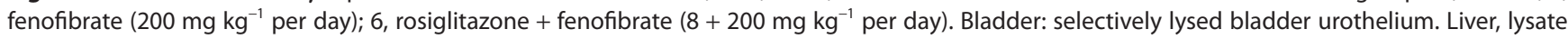
of whole liver. Heart, lysate of heart apex. Fat, lysate of white mesenterial fat. Muscle, lysate of red, outer, part of gastrocnemius muscle (skeletal muscle). All lysates comprised pools of five rats (treatment groups 4 and 6) or 10 rats (treatment group 1). (A) Western blots. PPAR $\alpha$ and PPAR $\gamma$ band location are indicated by arrows. Bottom panel, western blot with a cocktail of monoclonal antibodies against $\alpha$-tubulin, $\beta$-actin and GAPDH, to compare protein loading. (B) Coomassie-stained SDS-PAGE gel, using the same loading ( $\mu$ l lysate per well) as in panel (A). (C) Total protein load per lane in the western blots (panel A) and Coomassie gel (panel B), determined by amido black dot blot assay. 
receiving fenofibrate or the fenofibrate + rosiglitazone combination (Fig. 2A, compare for example PPAR $\alpha$ and PPAR $\gamma$ bands between the three lanes with heart lysate). Any effect of the PPAR agonists on PPAR expression levels was not investigated further in this work.

When band intensity (Fig. 2A) was normalized to protein content determined by the amido black dot blot assay (Fig. 2C), the bladder urothelium was found to express approximately 11-fold higher levels of PPAR $\alpha$ than the liver, which is generally held to have high PPAR $\alpha$ expression (Fig. 2, not shown in detail). Also, bladder urothelium expressed approximately 12-fold higher levels of PPAR $\gamma$ than fat, the archetypal PPAR $\gamma$-regulated tissue (Fig. 2, not shown in detail). Urothelium and heart were the only tissues to co-express PPAR $\alpha$ and PPAR $\gamma$, and urothelium was unique in the high level of coexpressed PPAR $\alpha$ and PPAR $\gamma$ (Fig. $2 \mathrm{~A}$ and $\mathrm{B}$, compare bladder and heart).

Finally, it should be mentioned that the western blotting technique is very well suited to comparison of PPAR protein levels between various tissues (Fig. 2), but due to limited sensitivity, the western blotting results in Fig. 2 do not contradict PPAR $\alpha$ expression in skeletal muscle (Braissant et al., 1996; Escher et al., 2001; Guan et al., 1997), nor rule out PPAR $\gamma$ expression in liver.
Inverse Gradients of PPAR $\alpha$ and PPAR $\gamma$ Expression through the Kidney, but Unique and Sex-specific PPAR $\gamma / \operatorname{PPAR} \alpha$ Ratio in the Urothelium

In the kidney, PPAR $\alpha$ expression increased from the papilla to the medulla and cortex (Fig. 3A). In contrast, PPAR $\gamma$ expression decreased from the papilla, through the medulla, to the cortex (Fig. 3A). Similarly to the liver (Fig. 2A), the PPAR $\alpha$ antibody produced double bands on kidney lysates (Fig. 3A).

Co-expression of PPAR $\alpha$ and PPAR $\gamma$ was thus found in all kidney samples (Fig. 3A). As the kidney cortex, medulla and pelvis lysates represented homogenized samples of whole tissue (see methods), it could not be determined whether the co-expression of PPAR $\alpha$ and PPAR $\gamma$ occurred at the single-cell level. In contrast, because bladder urothelium was selectively lysed (see Materials and Methods), the results in Figs $3 \mathrm{~A}$ and $2 \mathrm{~A}$ unequivocally showed co-expression of high levels of PPAR $\alpha$ and PPAR $\gamma$ by a single cell type, the bladder urothelium. These results are in agreement with a recent immunohistochemical study (Chopra et al., 2008).

Because of these inverse gradients of PPAR $\alpha$ and PPAR $\gamma$ expression through the kidney, the ratio of co-expression of PPAR $\alpha$ and

A

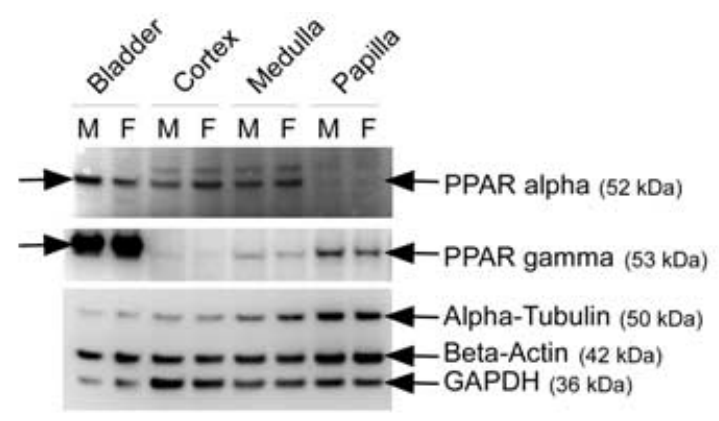

B
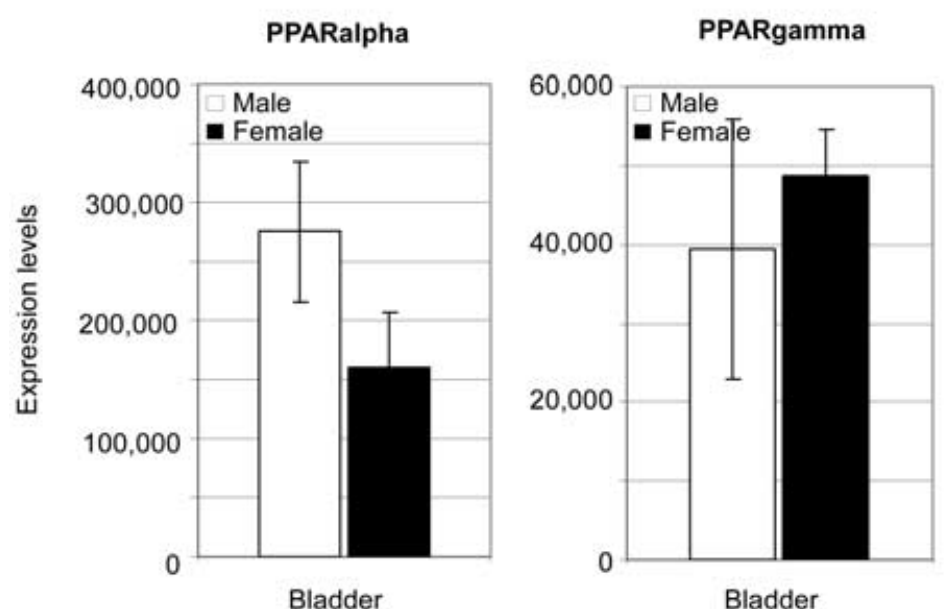

PPAR gamma/alpha ratio

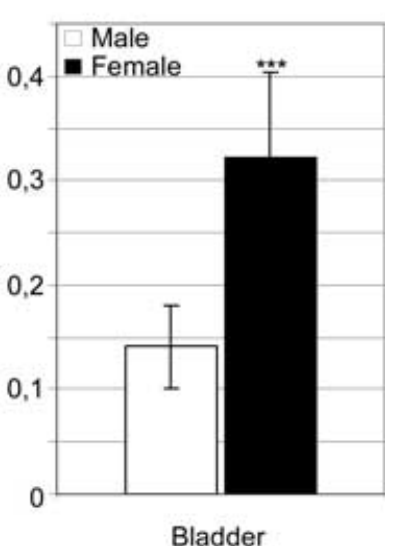

Figure 3. Comparison of PPAR $\alpha$ and PPAR $\gamma$ expression at different sites in urogenital tract, and between male and female rats. Bladder, selectively lysed bladder urothelium. Cortex, lysate of dissected kidney cortex. Medulla, lysate of dissected kidney medulla. Papilla, lysate of dissected kidney papilla. M, male rats. F, female rats. The rats were not treated with PPAR agonists, and all lysates comprised pools of five rats. (A) representative western blot. PPAR bands are indicated by arrows. All lanes were loaded with $3 \mu \mathrm{g}$ total protein, determined by amido black dot blot assay. Bottom panel, western blot with a cocktail of monoclonal antibodies against $\alpha$-tubulin, $\beta$-actin and GAPDH, to compare protein loading. (B) Quantitative analysis of $\operatorname{PPAR} \alpha$ and PPAR $\gamma$ expression in bladder urothelium, mean of three western blots. PPAR $\alpha$ and PPAR $\gamma$ band intensities were quantitated using MultiGauge software, and normalized to actin band intensities. ${ }^{* * *} P=0.03$ compared with PPAR $\gamma /$ PPAR $\alpha$ ratio in male rats, Student's $t$-test. 
PPAR $\gamma$ differed between kidney cortex, medulla and papilla (Fig. $3 \mathrm{~A})$. In the papilla, the PPAR $\gamma / \mathrm{PPAR} \alpha$ ratio was higher than in the cortex and medulla, and similar to the bladder urothelium (Fig. $3 \mathrm{~A}$, not shown in detail). This suggested that the kidney pelvis urothelium might be a major contributor to the PPAR $\alpha$ and PPAR $\gamma$ expression seen in the kidney papilla.

Finally, the PPAR $\alpha$ and PPAR $\gamma$ expression levels in kidney cortex and medulla appeared similar between male and female rats (Fig. $3 \mathrm{~A}$, not shown in detail). In contrast, in the bladder urothelium, females exhibited lower PPAR $\alpha$ expression and higher PPAR $\gamma$ expression levels than males (Fig. 3B), leading to significantly higher PPAR $\gamma /$ PPAR $\alpha$ ratios in the urothelium of female rats than in the urothelium of males (Fig. 3B).

\section{Endogenous Levels of the Egr-1 Transcription Factor in Rat Urothelium, Liver and Heart}

Quantition of expression of the zinc finger transcription factor Egr-1 (synonyms Zif268, NGFI-A, TIS8, Krox-24; Christy et al., 1988; Lemaire et al., 1988; Lim et al., 1987; Milbrandt 1987) was done by chemiluminescent western blotting, using the commercially available C-19 antipeptide rabbit immunoglobulin (see Materials and Methods). In preliminary experiments, six different commercially available Egr-1 antibodies were tested in western blotting on rat mammary gland adenocarcinoma cells (SMT/2A LNM) and human breast adenocarcinoma cells (MCF-7) stimulated with phorbol myristate acetate to induce Egr-1 expression, as well as liver lysates from rats treated with PPAR agonists to induce Egr-1 expression. The C-19 antipeptide rabbbit immunoglobulin proved the best reagent for western blot analysis of Egr-1 expression. C-19 provided clear bands of the expected size in human as well as rat cell lines and rat organ lysates (Fig. 4A). The C-19 immunoreactivity could be abolished by preadsorption with immunogen peptide (not shown). However, as we found extensive lot variation for C-19, all experiments were done with a single, pre-verified C-19 lot. Furthermore, the Egr-1 expression data reported in this study was verified by immunohistochemistry, using a different and monoclonal Egr-1 antibody (FLE, in preparation).

Egr-1 has previously been suggested as an early biomarker for the carcinogenic effect of dual-acting PPAR $\alpha+\gamma$ agonists in the rat urothelium (Egerod et al., 2005; Oleksiewicz et al., 2008), but endogenous Egr-1 levels in the urothelium have not been compared with levels in other rat tissue, where dual-acting PPAR $\alpha+$ $\gamma$ agonists do not exhibit carcinogenic effects. In the liver of healthy young rats not exposed to PPAR agonists, we found that Egr-1 was highly expressed (Fig. 4B and C), with approximately 14-fold lower levels in the urothelium, and approximately 60 -fold lower levels in the heart (Fig. 4B and C).

\section{High-level Induction of Egr-1 Occurs in the Liver by PPAR $\alpha$ but not PPAR $\gamma$ Agonists, and is not Recapitulated in other PPAR $\alpha$ Expressing Tissues}

The specific PPAR $\alpha$ agonist fenofibrate induced significant Egr-1 expression in the liver and heart (Figs $6 \mathrm{~A}$ and $7 \mathrm{~A}, P<0.001$ ). While $50 \mathrm{mg} \mathrm{kg}^{-1}$ fenofibrate caused maximal Egr-1 induction in the liver (Fig. 6D), Egr-1 induction in the heart by $50 \mathrm{mg} \mathrm{kg}^{-1}$ fenofibrate was not significant (Fig. 7C). Also, fold-induction levels of Egr-1 by fenofibrate were above 10-fold in the liver (Fig. 6D), but only 2-fold in the heart (Fig. 7C). Thus, liver was more sensitive than heart to Egr-1 induction by fenofibrate (Figs 6D and 7C). This was in agreement with higher PPAR $\alpha$ expression in the liver (Fig. $2 \mathrm{~A})$. In the urinary bladder urothelium, mild Egr-1 induction by fenofibrate was also apparent, albeit this did not reach statistical significance (Fig. 5A).

The PPAR $\gamma$ agonist rosiglitazone did not induce Egr-1 expression in liver (Fig. 6A) or heart (Fig. 7A). In bladder urothelium, mild

A

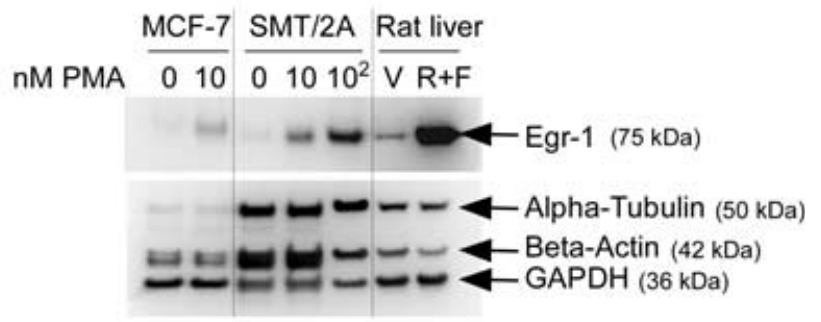

B

C
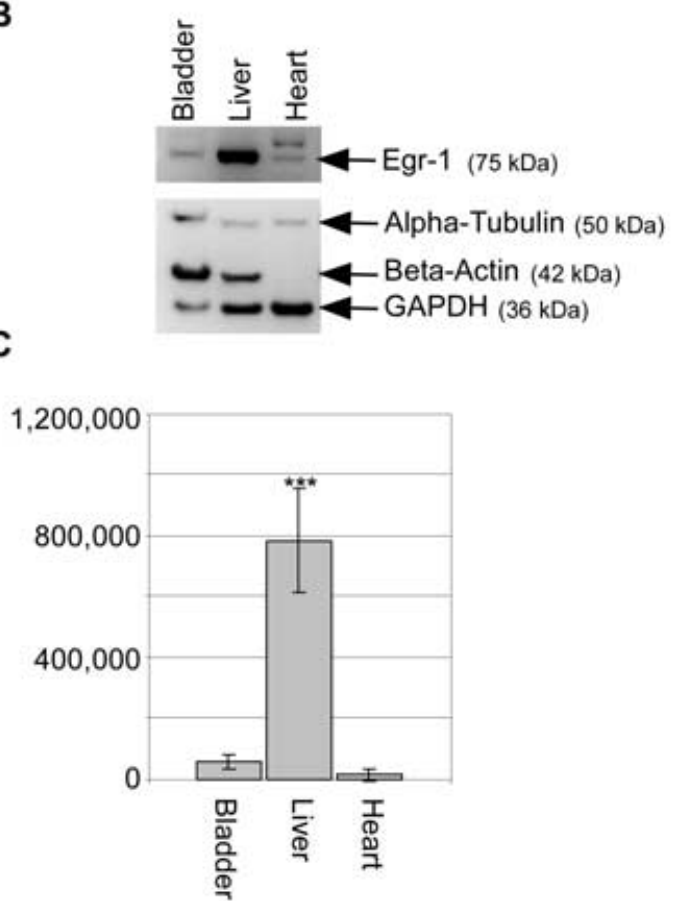

Figure 4. Endogenous levels of the Egr-1 transcription factor in rat urothelium, liver and heart. (A) To validate the species cross reactivity of the Egr-1 antibody, and validate the expected Egr-1 band location between human and rat, we used rat mammary gland adenocarcinoma cells (SMT/2A LNM) and human breast adenocarcinoma cells (MCF-7) stimulated in serum-free and Phenol Red-free Dulbecco's medium (GIBCO no. 11880-028) with different concentrations of phorbol myristate acetate (PMA) for 30-60 min, to induce Egr-1 expression. Rat liver lysates were from rats treated with $8 \mathrm{mg} \mathrm{kg}^{-1}$ rosiglitazone and $200 \mathrm{mg} \mathrm{kg}^{-1}$ fenofibrate $(\mathrm{R}+\mathrm{F})$ or vehicle $(\mathrm{V})$. Egr-1 band location is indicated by an arrow. $(B, C)$ Quantitation of endogenous Egr-1 expression levels in urothelium, liver and heart of vehicle-treated rats. The rats were treated orally for 7 days with the vehicle used to formulate rosiglitazone and fenofibrate, i.e. the rats were not exposed to PPAR agonists (see Materials and Methods). All lysates comprised pools of 10 rats (see Materials and Methods). All lanes were loaded with $8 \mu \mathrm{g}$ total protein determined by the amido black dot blot assay. The bar diagram shows quantitative analysis of Egr-1 expression, based on triplicate western determinations. ${ }^{* *} P<0.001$, comparison to bladder and heart lysates, repeated mesures one-way ANOVA with Tukey-Kramer post test. 


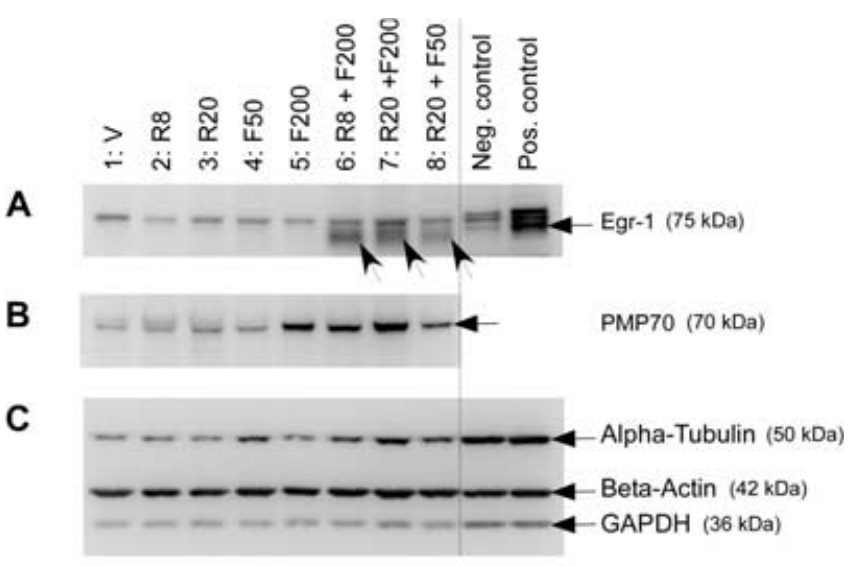

D

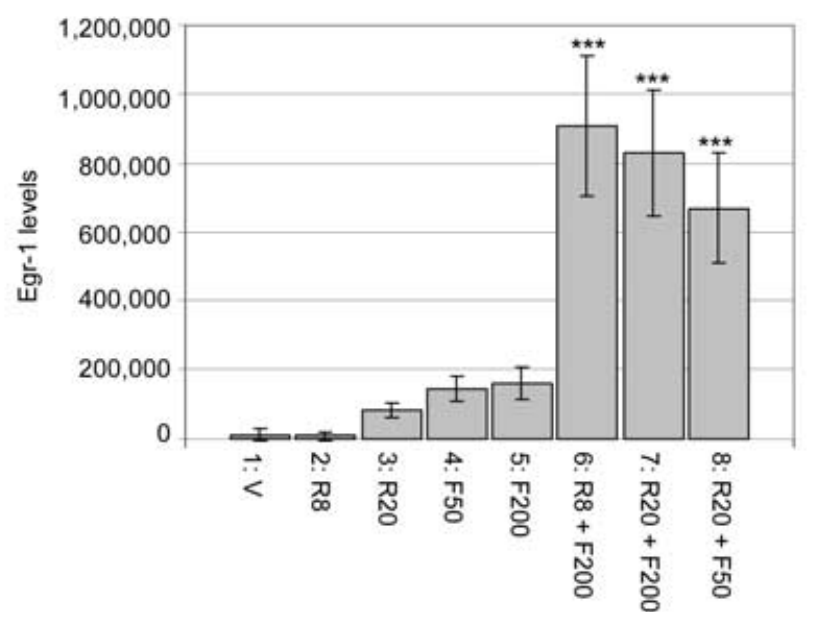

Figure 5. Synergy in Egr-1 induction in rat urinary bladder by oral treatment with PPAR $\alpha$ and PPAR $\gamma$ agonists in vivo. Numbers above lanes, treatment groups: 1 , vehicle; 2 , rosiglitazone ( $8 \mathrm{mg} \mathrm{kg}^{-1}$ per day); 3, rosiglitazone (20 mg kg${ }^{-1}$ per day); 4, fenofibrate $\left(50 \mathrm{mg} \mathrm{kg}^{-1}\right.$ per day); 5 , fenofibrate $\left(200 \mathrm{mg} \mathrm{kg}^{-1}\right.$ per day); 6 , rosiglitazone + fenofibrate $(8+$ $200 \mathrm{mg} \mathrm{kg}^{-1}$ per day); 7 , rosiglitazone + fenofibrate $\left(20+200 \mathrm{mg} \mathrm{kg}^{-1}\right.$ per day); 8 , rosiglitazone + fenofibrate $\left(20+50 \mathrm{mg} \mathrm{kg}^{-1}\right.$ per day). All lysates comprised pools of five rats (treatment groups 2 through 8) or 10 rats (treatment group 1). (A) Rat bladder urothelial lysates were analyzed by western immunoblotting with an anti-Egr-1 antibody. The expected Egr-1 band location is indicated by an arrow. Negative control lane, MCF-7 human breast adenocarcinoma cells (MCF-7) in serum-free and Phenol Red-free Dulbecco's medium (GIBCO no. 11880-028). Positive control lane, MCF-7 human breast adenocarcinoma cells (MCF-7) in serum-free medium stimulated with $10 \mathrm{~nm}$ phorbol myristate acetate for $1 \mathrm{~h}$. (B) Rat bladder urothelial lysates were analyzed by western immunoblotting with an anti-PMP70 antibody. (C) Western blot with a cocktail of monoclonal antibodies against $\alpha$-tubulin, $\beta$-actin and GAPDH, to compare protein loading. (D) Quantitative analysis of Egr-1 expression, mean of five replicate western blots. Egr-1 band intensities were normalized to actin band intensities, determined by MultiGauge software. ${ }^{* *} P$-value $<$ 0.001 , comparison to vehicle group, repeated-measures one-way ANOVA with Tukey-Kramer post test.

Egr-1 induction appeared to occur at $20 \mathrm{mg} \mathrm{kg}^{-1}$ but not $8 \mathrm{mg} \mathrm{kg}^{-1}$ rosiglitazone, albeit without statistical significance (Fig. 5A). Egr-1 induction could not be detected in fat and muscle lysates from treated or vehicle animals (not shown).

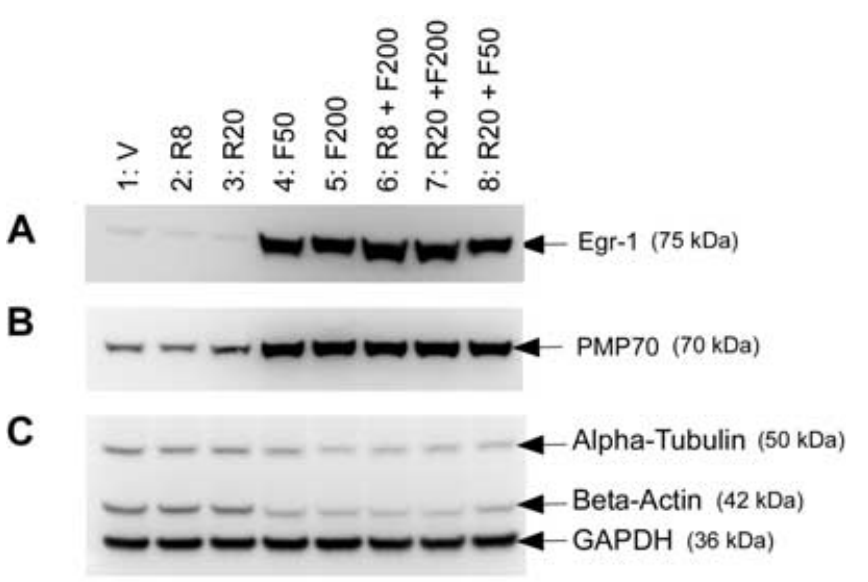

D

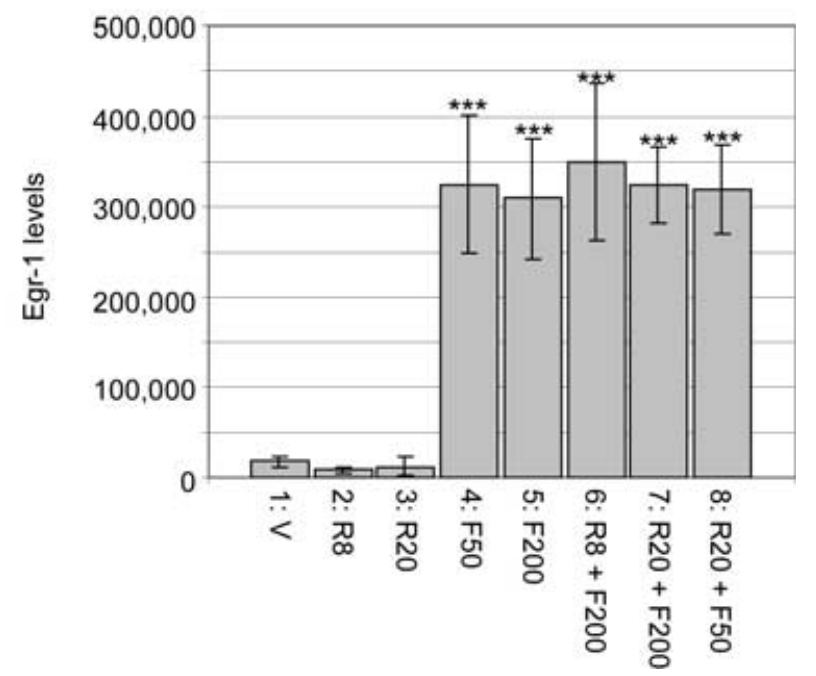

Figure 6. Egr- 1 is only induced by PPAR $\alpha$ agonists, but not PPAR $\gamma$ agonists, in rat liver. Numbers above lanes, treatment groups: 1 , vehicle; 2 , rosiglitazone ( $8 \mathrm{mg} \mathrm{kg}^{-1}$ per day); 3, rosiglitazone $\left(20 \mathrm{mg} \mathrm{kg}^{-1}\right.$ per day); 4 , fenofibrate (50 mg kg-1 per day); 5, fenofibrate (200 $\mathrm{mg} \mathrm{kg}^{-1}$ per day); 6 , rosiglitazone + fenofibrate $\left(8+200 \mathrm{mg} \mathrm{kg}^{-1}\right.$ per day); 7 , rosiglitazone + fenofibrate $\left(20+200 \mathrm{mg} \mathrm{kg}^{-1}\right.$ per day); 8 , rosiglitazone + fenofibrate $\left(20+50 \mathrm{mg} \mathrm{kg}^{-1}\right.$ per day). All lysates comprised pools of five rats (treatment groups 2-8) or 10 rats (treatment group 1). (A) Rat liver lysates were analyzed by western immunoblotting with an anti-Egr-1 antibody. The expected Egr-1 band location is indicated by an arrow. (B) Rat liver lysates were analyzed by western immunoblotting with an anti-PMP70 antibody. (C) Western blot with a cocktail of monoclonal antibodies against $\alpha$-tubulin, $\beta$-actin and GAPDH, to compare protein loading. (D) Quantitative analysis of Egr-1 expression, mean of five replicate western blots. Egr-1 band intensities were normalized to actin band intensities, determined by MultiGauge software. ${ }^{* * *} P$-value $<0.001$, comparison to vehicle group, repeated-measures one-way ANOVA with Tukey-Kramer post test.

\section{PPAR $\alpha$ Agonist Treatment Induces the PMP70 Marker of Peroxisomal Proliferation in some (Liver, Urothelium) but not all (Heart) PPAR $\alpha$-expressing Tissue}

The peroxisome membrane protein 70 (PMP70) has been described as a specific marker for PPAR $\alpha$ activation and peroxisome proliferation (Colton et al., 2004; Yang et al., 2008). Accordingly, in the liver, maximal PMP70 induction was observed 

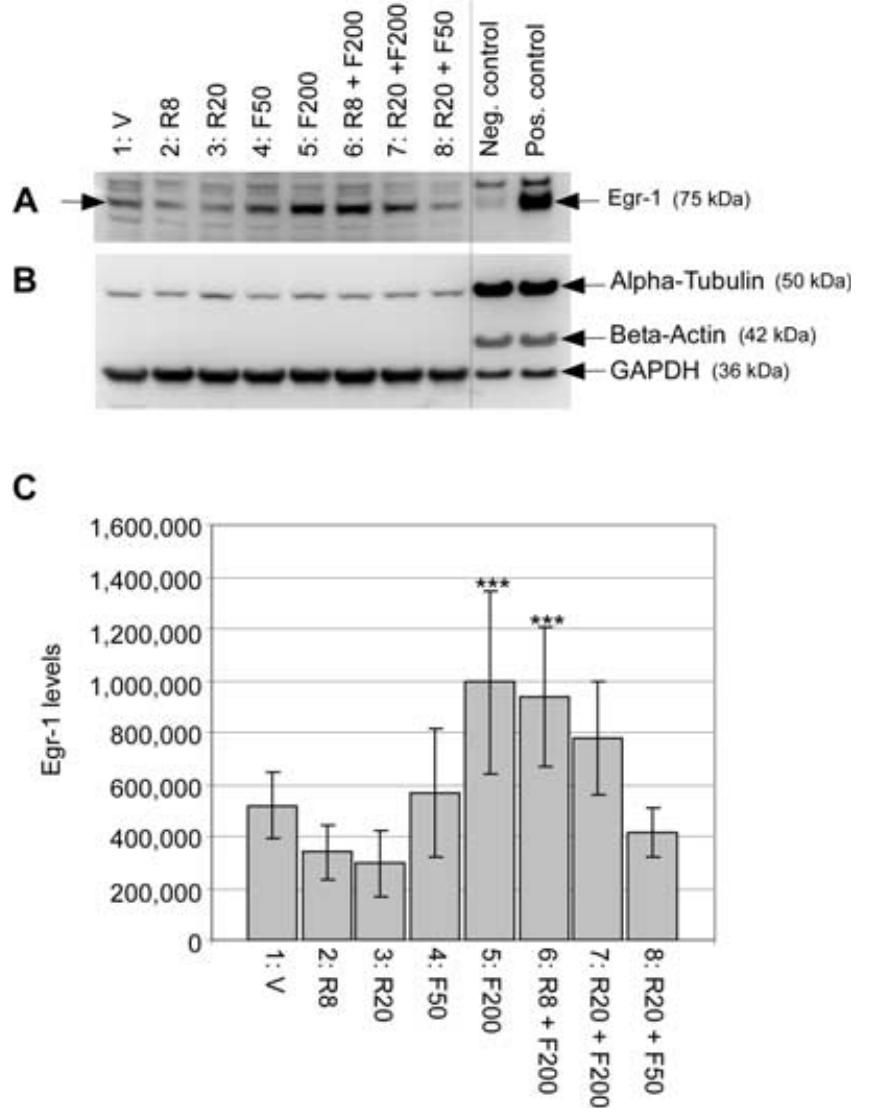

Figure 7. Egr-1 is only induced by PPAR $\alpha$ agonists, but not PPAR $\gamma$ agonists, in rat heart. Numbers above lanes, treatment groups; 1 , vehicle; 2 , rosiglitazone ( $8 \mathrm{mg} \mathrm{kg}^{-1}$ per day); 3, rosiglitazone ( $20 \mathrm{mg} \mathrm{kg}^{-1}$ per day); 4 , fenofibrate (50 mg kg-1 per day); 5 , fenofibrate (200 mg kg-1 per day); 6 , rosiglitazone + fenofibrate $\left(8+200 \mathrm{mg} \mathrm{kg}^{-1}\right.$ per day $) ; 7$, rosiglitazone + fenofibrate $\left(20+200 \mathrm{mg} \mathrm{kg}^{-1}\right.$ per day); 8 , rosiglitazone + fenofibrate $\left(20+50 \mathrm{mg} \mathrm{kg}^{-1}\right.$ per day). All lysates comprised pools of five rats (treatment groups 2-8) or 10 rats (treatment group 1). (A) Rat heart lysates were analyzed by western immunoblotting with an anti-Egr-1 antibody. The expected Egr-1 band location is indicated by an arrow. Negative control lane, SMT/2A rat adenocarcinoma cells. Positive control lane, SMT/2A rat adenocarcinoma cells stimulated with phorbol myristate acetate. (B) Western blot with a cocktail of monoclonal antibodies against $\alpha$-tubulin, $\beta$-actin and GAPDH, to compare protein loading. (C) Quantitative analysis of Egr-1 expression, mean of five replicate western blots. Egr-1 band intensities were normalized to actin band intensities, determined by MultiGauge software. ${ }^{* * *} P$-value $<0.001$, comparison to vehicle group, repeated measures one-way ANOVA with Tukey-Kramer post test.

in the $50 \mathrm{mg} \mathrm{kg}^{-1}$ fenofibrate group (Fig. 6B), i.e. PMP70 and Egr-1 both exhibited maximal induction at $50 \mathrm{mg} \mathrm{kg}^{-1}$ fenofibrate (Fig. 6A and B), a dose level used in pharmacological experiments (Besson et al., 2005; Chakrabarti et al., 2003). In contrast, in the urothelium, PMP70 induction required $200 \mathrm{mg} \mathrm{kg}^{-1}$ fenofibrate (Fig. 5B). Thus, liver was more sensitive than bladder urothelium to PPAR $\alpha$ activation (Figs 5B and 6B), despite PPAR $\alpha$ expression being higher in the bladder urothelium than in the liver (Fig. 2).

Finally, PMP70 was not induced by fenofibrate in the heart (not shown). Also, PMP70 expression was not induced by rosiglitazone in any of the examined tissue (Figs 5 and 6 and not shown).

\section{Egr-1 Induction in Urinary Bladder Urothelium, but not Heart or Liver, through Positive Interaction between PPAR $\alpha$ and PPAR $\gamma$ Agonists}

As mentioned above, in urinary bladder urothelium, treatment with fenofibrate or rosiglitazone alone induced only mild Egr-1 expression, which did not reach statistical significance (Fig. 5A and $D$ ). However combination treatment with rosiglitazone and fenofibrate did induce significant Egr-1 expression (Fig. 5A and $D, P<0.001)$. The effect of the rosiglitazone and fenofibrate combination was significantly higher than the effect of either drug alone, i.e. rosiglitazone and fenofibrate exhibited synergy with regards to Egr-1 induction in the bladder urothelium (Fig. 5A and D). Compared with animals receiving a combination of $8 \mathrm{mg} \mathrm{kg}^{-1}$ rosiglitazone and $200 \mathrm{mg} \mathrm{kg}^{-1}$ fenofibrate, Egr-1 induction appeared slightly lessened by increasing rosiglitazone to $20 \mathrm{mg} \mathrm{kg}^{-1}$ while maintaining fenofibrate at $200 \mathrm{mg} \mathrm{kg}^{-1}$, or increasing rosiglitazone to $20 \mathrm{mg} \mathrm{kg}^{-1}$ while reducing fenofibrate to $50 \mathrm{mg} \mathrm{kg}^{-1}$ (Fig. 5A and D). In contrast to Egr-1, synergy between rosiglitazone and fenofibrate was not seen for PMP70 induction in the urinary bladder (Fig. 5B).

Finally, in contrast to the bladder, synergy between rosiglitazone and fenofibrate with regards to Egr-1 expression was not seen in the liver or heart (Figs 6 and 7).

\section{DISCUSSION}

We showed for the first time that PPAR $\alpha$ and PPAR $\gamma$ expression levels in the rat urinary bladder urothelium are unexpectedly high (Figs 2 and 3). Urothelial expression of PPAR $\gamma$ was approximately 10 -fold higher than in reference organs such as fat, heart and muscle (Fig. 2). Urothelial expression of PPAR $\alpha$ was approximately 10-fold higher than in liver (Fig. 2), and comparable to kidney cortex and medulla (Fig. 3). Thus, the urothelium appeared unique in combining PPAR $\alpha$ and PPAR $\gamma$ co-expression with high PPAR $\alpha$ and PPAR $\gamma$ expression levels (Figs 2 and 3). We speculate that this could contribute to the apparent sensitivity of the rat urothelium to carcinogenesis by dual-acting PPAR $\alpha+\gamma$ agonists (Oleksiewicz et al., 2008). Additionally, while the balance between $\operatorname{PPAR} \alpha$ and PPAR $\gamma$ expression in the kidney cortex and medulla was similar between male and female rats, it differed between sexes in the urothelium, with females exhibiting significantly higher PPAR $\gamma /$ PPAR $\alpha$ ratios than males (Fig. 3). Thus, PPAR expression levels may also explain sex differences in susceptibility to the bladder-carcinogenic effects of dual-acting PPAR $\alpha+$ agonists in rats.

In similar vein, it should be mentioned that lysates of bladder urothelial cells were compared with organ lysates containing mixed cell populations from liver, heart, fat and skeletal muscle. Thus, while our study unequivocally showed that urothelial cells co-express PPAR $\alpha$ and PPAR $\gamma$, inferences about cellular coexpression of PPAR $\alpha$ and PPAR $\gamma$ in liver, heart, fat and skeletal muscle cannot be made based on our study.

Crosstalk between PPAR $\alpha$ and PPAR $\gamma$ in the rat bladder urothelium was explored by comparing rats treated with fenofibrate, rosiglitazone or fenofibrate + rosiglitazone combinations (Fig. 5). Rosiglitazone and fenofibrate are recognized model compounds for specific activation of PPAR $\alpha$ and PPAR $\gamma$, respectively, in rats as well as humans (Bajaj et al., 2007; De et al., 2007; Iglarz et al., 2003; Rose et al., 2007; Wagner et al., 2005). Furthermore, in both rats and humans, rosiglitazone and fenofibrate combination is a 
recognized approach for simultaneous activation of PPAR $\alpha$ and PPAR $\gamma$ (Bajaj et al., 2007; De et al., 2007; Iglarz et al., 2003; Rose et al., 2007; Wagner et al., 2005). The doses in our study (Table 1) corresponded to high pharmacological doses (Besson et al., 2005; Chakrabarti et al., 2003; De Souza et al., 2006; De et al., 2007; Iglarz et al., 2003; Rose et al., 2007), to ensure saturation of PPARs across organ systems, and minimize the risk of drug distribution phenomena confounding comparison of PPAR activation effects between organs. Our main endpoint to evaluate PPAR crosstalk was the transcription factor Egr-1. Egr-1 was found to be induced at mRNA as well as protein level in the bladder urothelium of rats following ragaglitazar treatment, and was suggested to be a candidate biomarker for the carcinogenic effect of dual-acting PPAR agonists in the rat bladder urothelium (Egerod et al., 2005; Oleksiewicz et al., 2008).

In the urothelium, Egr-1 expression was not induced by $8 \mathrm{mg} \mathrm{kg}^{-1}$ rosiglitazone, but was mildly and nonsignificantly induced by $20 \mathrm{mg} \mathrm{kg}^{-1}$ rosiglitazone, as well as by fenofibrate at both dose levels (Fig. 5). Strikingly, in animals receiving a combination of $8 \mathrm{mg} \mathrm{kg}^{-1}$ rosiglitazone and $200 \mathrm{mg} \mathrm{kg}^{-1}$ fenofibrate, a strong Egr-1 expression was seen, significantly above the effect of either drug alone (Fig. 5). Thus, fenofibrate and rosiglitazone exhibited positive interaction (in this case synergy) as regards induction of Egr-1 expression in the rat bladder urothelium (Fig. 5). Some PPAR $\alpha(\mathrm{Wy}-14,643)$ as well as PPAR $\gamma$ agonists (troglitazone) are known to increase Egr-1 expression by nonspecific mechanisms not mediated by PPAR activation (Baek et al., 2003, 2004; Chintharlapalli et al., 2005; Pauley et al., 2002). We consider it highly unlikely that the induction of Egr-1 expression observed in the urothelium of animals co-administered rosiglitazone and fenofibrate represented unspecific (offtarget, PPAR-independent) effects of rosiglitazone and fenofibrate, for the following reasons: first, while troglitazone caused increased Egr-1 expression by PPAR $\gamma$-independent mechanisms in HCT-116 human colon cancer cells, rosiglitazone did not (Baek et al., 2003). Second, in animals receiving $200 \mathrm{mg} \mathrm{kg}^{-1}$ fenofibrate, co-administration of $8 \mathrm{mg} \mathrm{kg}^{-1}$ rosiglitazone caused synergistic induction of Egr-1 in the urothelium (Fig. 5), but increasing rosiglitazone to $20 \mathrm{mg} \mathrm{kg}^{-1}$ did not increase, and in fact slightly decreased, Egr-1 induction (Fig. 5). This observed saturation at $8 \mathrm{mg} \mathrm{kg}^{-1}$ rosiglitazone would be expected for PPAR $\gamma$-dependent effects, but not for nonspecific effects. Third, in those organs where fenofibrate caused significant Egr-1 induction on its own (Figs 6 and 7, heart and liver), the organ with high PPAR $\alpha$ expression (liver, Figs 2 and 6) exhibited higher fold-induction of Egr-1, and at lower fenofibrate doses, than the organ with low PPAR $\alpha$ expression (heart, Figd 2 and 7), supporting a specific, PPAR $\alpha$-dependent effect of fenofibrate in the liver. Fourth, in tissue where co-expression of PPAR $\alpha$ and PPAR $\gamma$ was detected (Fig. 2, urothelium and heart), synergy between fenofibrate and rosiglitazone was detected in the tissue with high PPAR $\alpha$ and PPAR $\gamma$ expression (urothelium, Figs 2 and 5 ), but not the tissue with low PPAR $\alpha$ and PPAR $\gamma$ expression (heart, Figs 2 and 7), arguing against the Egr-1 induction representing PPAR-independent effects of rosiglitazone and fenofibrate.

Finally, it should be mentioned that while a synergistic effect was seen in this study between fenofibrate and rosiglitazone in causing Egr-1 induction in the rat urothelium (Fig. 5), in other studies, the effect appeared additive (Egerod et al., 2005 and not shown). Thus, all avaible data supports a positive interaction between PPAR $\alpha$ and PPAR $\gamma$ in terms of Egr- 1 induction in the rat urothelium, with additive as well as synergistic effects being observed. The molecular mechanisms responsible for the positive interaction between PPAR $\alpha$ and PPAR $\gamma$ signaling in the rat bladder urothelium remain to be determined. However, it has been proposed that crosstalk between nuclear transcription factor receptors such as the PPARs, the estrogen receptor and the thyroid hormone receptor is the rule rather than the exception, and in at least some cases, sharing of transcriptome protein binding partners or binding to the same DNA response sequence is involved (Carey 1998; Schulman et al., 1998).

Egr-1 induction by fenofibrate and rosiglitazone was not observed in fat and skeletal muscle (not shown), but did occur in urothelium, liver and heart (Figs 5-7). Liver, fat and urothelium, but not heart and skeletal muscle, are targets for the carcinogenic effecs of specific PPAR $\alpha$ agonists, specific PPAR $\gamma$ agonists, and dual-acting PPAR $\alpha+\gamma$ agonists, respectively, in the rat (Oleksiewicz et al., 2008). Thus, Egr-1 induction was seen in two of three carcinogenicity target tissues, and one of two tissues where cancer is not expected in PPAR agonist-treated rats; i.e. Egr-1 expression per se is expected to be neither sufficient, nor required, for the carcinogenic effect of PPAR $\alpha$ and $\gamma$ agonists. This is fully in accordance with the known involvement of Egr-1 in normal physiological processes in for example the heart (Gupta et al., 1991; Jin et al., 2000; Shamim et al., 1999), as well as with the known cancer type-specificity of transcription factor upregulation; i.e. even though overexpression of a given transcription factor may be important for certain cancer forms in some organs, the same transcription factor is not thereby expected to be involved in all cancers forms across different organs. We found that in rats not exposed to PPAR agonists, endogenous Egr-1 expression was highest in liver, lower in urothelium, and lowest in heart (Fig. 4B and C). Thus, it seems plausible that the functional roles of Egr-1 may differ between liver, urothelium and heart. Also, compared with the vehicle group, PPAR agonist-induced Egr-1 expression was above 10-fold in liver and urothelium, but only 2-fold in the heart (Figs 5-7). Thus, endogenous Egr-1 expression levels, as well as the magnitude of Egr-1 induction following dual PPAR $\alpha+\gamma$ activation, differentiated between carcinogenicity target tissue (liver, urothelium) and a tissue where PPAR agonist toxicity, but not cancer, is seen (heart) (Figs 5-7).

The PMP70 peroxisomal membrane protein is a marker for peroxisome proliferation in rats and primates (Colton et al., 2004; Kwanyuen et al., 2006; Wilcke and Alexson, 2001). Peroxisome proliferation and PMP70 expression is induced in the livers of rodents treated with PPAR $\alpha$ agonists, and oxidative stress by peroxisomes has been suggested to be involved in the hepatocarcinogenesis by PPAR $\alpha$ agonists in rodents (Yeldandi et al., 2000). In agreement with this, we observed upregulation of PMP70 expression in the liver of rats treated with $50 \mathrm{mg} \mathrm{kg}^{-1}$ fenofibrate (Fig. 6). Interestingly, PMP70 was also upregulated by fenofibrate in the urothelium, albeit this required a higher fenofibrate dose than PMP70 induction in the liver, $200 \mathrm{mg} \mathrm{kg}^{-1}$ (Figs 5 and 6). Similarly, peroxisomal $\beta$ oxidation was found to be induced in the kidney and heart by the PPAR $\alpha$ agonist ciprofibrate, but to a lesser extent than in the liver (Cook et al., 2000). To our knowledge, this is the first indication that PPAR $\alpha$ activation may cause peroxisome proliferation in the rat urothelium. As PMP70 but not Egr-1 were induced by fenofibrate, this underscored that PPAR $\alpha$ activation was not sufficient for Egr-1 induction in the urothelium (Fig. 5), and that Egr-1 induction in animals co-administered fenofibrate and rosiglitazone was a true positive crosstalk effect (Fig. 5), as discussed above. Also, these data open the possibility that oxidative stress may contribute to the carcinogenic effect of 
dual-acting PPAR $\alpha+\gamma$ agonists in the rat urothelium. This hypothesis is indirectly supported by the observation that male rats in some cases appeared more sensitive than females to the bladder carcinogenic effect of dual-acting PPAR $\alpha+\gamma$ agonists (Lima et al., 2006), and male rats expressed significantly more PPAR $\alpha$ (which mediates PMP70 induction) relative to PPAR $\gamma$ than did female rats (Fig. 4). Also, the relevance of PPAR $\alpha$ activation for urothelial cancer initiation (by for example free radical production) is indirectly supported by the finding that rosiglitazone, a specific PPAR $\gamma$ agonist, supports cancer promotion rather than initiation (Lubet et al., 2008).

Interestingly, the magnitude of Egr-1 induction, and the presence of PMP70 induction, differed between urothelium, liver and heart of rats co-administered rosiglitazone and fenofibrate (Figs 5-7). Thus, PMP70 represents a new candidate biomarker for the carcinogenic effect of dual-acting PPAR $\alpha+\gamma$ agonists in the rat urothelium, and the combination of the Egr-1 and PMP70 candidate biomarkers may improve the predictive value as regards carcinogenic effect of dual-acting PPAR $\alpha+\gamma$ agonists in the rat urothelium.

\section{Acknowledgments}

Vibeke Ladas, Rikke Pernille Wentzel, Ulla Thinggaard and Jonas Steenbuch Krabbe are thanked for technical assistance. Hanne Vikjær Andersen is thanked for crucial help in planning and facilitating animal experiment. Erik Max Wulff, Per Sauerberg and Anja Benfeldt are thanked for help with drug formulation. Jennifer Butcher, Jennifer Southgate, Inger Thorup and Lars Iversen are thanked for stimulating discussions. Lars Strange is thanked for statistical advice.

\section{REFERENCES}

Baek SJ, Wilson LC, Hsi LC, Eling TE. 2003. Troglitazone, a peroxisome proliferator-activated receptor gamma (PPAR gamma) ligand, selectively induces the early growth response-1 gene independently of PPAR gamma. A novel mechanism for its anti-tumorigenic activity. J. Biol. Chem. 278: 5845-5853.

Baek SJ, Kim JS, Nixon JB, DiAugustine RP, Eling TE. 2004. Expression of NAG-1, a transforming growth factor-beta superfamily member, by troglitazone requires the early growth response gene EGR-1. J. Biol. Chem. 279: 6883-6892.

Bajaj M, Suraamornkul S, Hardies LJ, Glass L, Musi N, DeFronzo RA. 2007. Effects of peroxisome proliferator-activated receptor (PPAR)-alpha and PPAR-gamma agonists on glucose and lipid metabolism in patients with type 2 diabetes mellitus. Diabetologia 50: 1723-1731.

Berger JP, Akiyama TE, Meinke PT. 2005. PPARs: therapeutic targets for metabolic disease. Trends Pharmacol. Sci. 26: 244-251.

Besson VC, Chen XR, Plotkine M, Marchand-Verrecchia C. 2005. Fenofibrate, a peroxisome proliferator-activated receptor alpha agonist, exerts neuroprotective effects in traumatic brain injury. Neurosci. Lett. 388: 7-12.

Braissant O, Foufelle F, Scotto C, Dauta M, Wahli W. 1996. Differential expression of peroxisome proliferator-activated receptors (PPARs): tissue distribution of PPAR-alpha, -beta, and -gamma in the adult rat. Endocrinology 137: 354-366.

Brand CL, Sturis J, Gotfredsen CF, Fleckner J, Fledelius C, Hansen BF, Andersen B, Ye JM, Sauerberg P, Wassermann K. 2003. Dual PPARalpha /gamma activation provides enhanced improvement of insulin sensitivity and glycemic control in ZDF rats. Am. J. Physiol. Endocrinol. Metab. 284: E841-E854.

Carey M. 1998. The enhanceosome and transcriptional synergy. Cell. 92: $5-8$.

Chakrabarti R, Vikramadithyan RK, Misra P, Hiriyan J, Raichur S, Damarla RK, Gershome C, Suresh J, Rajagopalan R. 2003. Ragaglitazar: a novel
PPAR alpha PPAR gamma agonist with potent lipid-lowering and insulin-sensitizing efficacy in animal models. Br. J. Pharmacol. 140: 527-537.

Chintharlapalli S, Papineni S, Baek SJ, Liu S, Safe S. 2005. 1,1-Bis(3'-indolyl)1 -( $p$-substitutedphenyl)methanes are peroxisome proliferatoractivated receptor gamma agonists but decrease HCT-116 colon cancer cell survival through receptor-independent activation of early growth response-1 and nonsteroidal anti-inflammatory drugactivated gene-1. Mol. Pharmacol. 68: 1782-1792.

Chopra B, Hinley J, Oleksiewicz MB, Southgate J. 2008. Trans-species comparison of PPAR and RXR expression by rat and human urothelial tissues. Toxicol.Pathol. 36: 485-495.

Christy BA, Lau LF, Nathans D. 1988. A gene activated in mouse 3 T3 cells by serum growth factors encodes a protein with 'zinc finger' sequences. Proc. Natl Acad. Sci. USA 85: 7857-7861.

Colton HM, Falls JG, Ni H, Kwanyuen P, Creech D, McNeil E, Casey WM, Hamilton G, Cariello NF. 2004. Visualization and quantitation of peroxisomes using fluorescent nanocrystals: treatment of rats and monkeys with fibrates and detection in the liver. Toxicol. Sci. 80: 183-192.

Cook WS, Yeldandi AV, Rao MS, Hashimoto T, Reddy JK. 2000. Less extrahepatic induction of fatty acid beta-oxidation enzymes by PPAR alpha. Biochem. Biophys. Res. Commun. 278: 250-257.

De CC, Amiri F, Iglarz M, Cohn JS, Touyz RM, Schiffrin EL. 2007. Synergistic vascular protective effects of combined low doses of PPARalpha and PPARgamma activators in angiotensin II-induced hypertension in rats. Br. J. Pharmacol. 151: 45-53.

De Souza AT, Cornwell PD, Dai X, Caguyong MJ, Ulrich RG. 2006. Agonists of the peroxisome proliferator-activated receptor alpha induce a fiber-type-selective transcriptional response in rat skeletal muscle. Toxicol. Sci. 92: 578-586.

Dieckmann-Schuppert A, Schnittler HJ. 1997. A simple assay for quantification of protein in tissue sections, cell cultures, and cell homogenates, and of protein immobilized on solid surfaces. Cell Tissue Res. 288: 119-126.

Dreyer C, Krey G, Keller H, Givel F, Helftenbein G, Wahli W. 1992. Control of the peroxisomal beta-oxidation pathway by a novel family of nuclear hormone receptors. Cell 68: 879-887.

Egerod FL, Nielsen HS, Iversen L, Thorup I, Storgaard T, Oleksiewicz MB. 2005. Biomarkers for early effects of carcinogenic dual-acting PPAR agonists in rat urinary bladder urothelium in vivo. Biomarkers. 10: 295-309.

Escher P, Braissant O, Basu-Modak S, Michalik L, Wahli W, Desvergne B. 2001. Rat PPARs: quantitative analysis in adult rat tissues and regulation in fasting and refeeding. Endocrinology 142: 4195-4202.

Fiévet C, Fruchart JC, Staels B. 2006. PPARalpha and PPARgamma dual agonists for the treatment of type 2 diabetes and the metabolic syndrome. Curr. Opin. Pharmacol. 6: 606-614.

Guan Y, Zhang Y, Davis L, Breyer MD. 1997. Expression of peroxisome proliferator-activated receptors in urinary tract of rabbits and humans. Am. J. Physiol. 273: F1013-F1022.

Gupta MP, Gupta M, Zak R, Sukhatme VP. 1991. Egr-1, a serum-inducible zinc finger protein, regulates transcription of the rat cardiac alphamyosin heavy chain gene. J. Biol. Chem. 266: 12813-12816.

Henkel AW, Bieger SC. 1994. Quantification of proteins dissolved in an electrophoresis sample buffer. Anal. Biochem. 223: 329-331.

Iglarz M, Touyz RM, Viel EC, Paradis P, Amiri F, Diep QN, Schiffrin EL. 2003. Peroxisome proliferator-activated receptor-alpha and receptorgamma activators prevent cardiac fibrosis in mineralocorticoiddependent hypertension. Hypertension 42: 737-743.

Jin Y, Sheikh F, Detillieux KA, Cattini PA. 2000. Role for early growth response-1 protein in alpha(1)-adrenergic stimulation of fibroblast growth factor-2 promoter activity in cardiac myocytes. Mol. Pharmacol. 57: 984-990.

Kwanyuen P, Witherspoon SM, Creech DR, Colton HM, Falls JG, Cariello NF. 2006. Flow cytometric assessment of peroxisome proliferation from frozen liver of fibrate-treated monkeys. Int. J. Toxicol. 25: 41-47.

Lemaire P, Revelant O, Bravo R, Charnay P. 1988. Two mouse genes encoding potential transcription factors with identical DNA-binding domains are activated by growth factors in cultured cells. Proc. Natl Acad. Sci. USA 85: 4691-4695.

Lemberger T, Saladin R, Vazquez M, Assimacopoulos F, Staels B, Desvergne B, Wahli W, Auwerx J. 1996. Expression of the peroxisome proliferator-activated receptor alpha gene is stimulated by stress and follows a diurnal rhythm. J. Biol. Chem. 271: 1764-1769. 
Lim RW, Varnum BC, Herschman HR. 1987. Cloning of tetradecanoyl phorbol ester-induced 'primary response' sequences and their expression in density-arrested Swiss 3T3 cells and a TPA non-proliferative variant. Oncogene 1: 263-270.

Lima BS, Dominick M, Iversen L, Oleksiewicz MB. 2006. Peroxisome proliferators activated receptors (PPARs) agonists and rodent tumorigenesis: updating the discussions. DIA 42nd Annual Meeting, BT Biotechnology/NC Nonclinical Labaroratory Safety, 299D.

Lubet RA, Fischer SM, Steele VE, Juliana MM, Desmond R, Grubbs CJ. 2008. Rosiglitazone, a PPAR gamma agonist: potent promoter of hydroxybutyl(butyl)nitrosamine-induced urinary bladder cancers. Int. J. Cancer 123: 2254-2259.

Michalik L, Auwerx J, Berger JP, Chatterjee VK, Glass CK, Gonzalez FJ, Grimaldi PA, Kadowaki T, Lazar MA, O'Rahilly S, Palmer CN, Plutzky J, Reddy JK, Spiegelman BM, Staels B, Wahli W. 2006. International Union of Pharmacology. LXI. Peroxisome proliferator-activated receptors. Pharmacol. Rev. 58: 726-741.

Milbrandt J. 1987. A nerve growth factor-induced gene encodes a possible transcriptional regulatory factor. Science 238: 797-799.

Oleksiewicz MB, Southgate J, Iversen L. Egerod FL. 2008. Rat urinary bladder carcinogenesis by dual-acting PPAR alpha + gamma agonists. PPAR Research, Epub 28 January.

Passilly P, Schohn H, Jannin B, Cherkaoui MM, Boscoboinik D, Dauta M, Latruffe N. 1999. Phosphorylation of peroxisome proliferatoractivated receptor alpha in rat Fao cells and stimulation by ciprofibrate. Biochem. Pharmacol. 58: 1001-1008.

Pauley CJ, Ledwith BJ, Kaplanski C. 2002. Peroxisome proliferators activate growth regulatory pathways largely via peroxisome proliferatoractivated receptor alpha-independent mechanisms. Cell Signal. 14: 351-358.

Reifel-Miller A, Otto K, Hawkins E, Barr R, Bensch WR, Bull C, Dana S, Klausing K, Martin JA, Rafaeloff-Phail R, Rafizadeh-Montrose $C$, Rhodes G, Robey R, Rojo I, Rungta D, Snyder D, Wilbur K, Zhang T,
Zink R, Warshawsky A, Brozinick JT. 2005. A peroxisome proliferatoractivated receptor alpha/gamma dual agonist with a unique in vitro profile and potent glucose and lipid effects in rodent models of type 2 diabetes and dyslipidemia. Mol. Endocrinol. 19: 1593-1605.

Rose M, Balakumar P, Singh M. 2007. Ameliorative effect of combination of fenofibrate and rosiglitazone in pressure overload-induced cardiac hypertrophy in rats. Pharmacology 80: 177-184.

Schulman IG, Shao G, Heyman RA. 1998. Transactivation by retinoid X receptor-peroxisome prolifaretor-activated receptor gamma (PPARg) heterodimers: intermolecular synergy requires only the PPARg hormone-dependent activation function. Mol. Cell Biol. 18: 3483-3494.

Shalev A, Siegrist-Kaiser CA, Yen PM, Wahli W, Burger AG, Chin WW, Meier CA. 1996. The peroxisome proliferator-activated receptor alpha is a phosphoprotein: regulation by insulin. Endocrinology 137: 4499-4502.

Shamim A, Pelzer T, Groho C, Neyses L. 1999. Induction of Egr-1 mRNA and protein by endothelin 1, angiotensin II and norepinephrine in neonatal cardiac myocytes. Mol. Cell Biochem. 195: 11-17.

Wagner JA, Larson PJ, Weiss S, Miller JL, Doebber TW, Wu MS, Moller DE, Gottesdiener KM. 2005. Individual and combined effects of peroxisome proliferator-activated receptor and \{gamma\} agonists, fenofibrate and rosiglitazone, on biomarkers of lipid and glucose metabolism in healthy nondiabetic volunteers. J. Clin. Pharmacol. 45: 504-513.

Wilcke M, Alexson SE. 2001. Differential induction of peroxisomal populations in subcellular fractions of rat liver. Biochim. Biophys. Acta. 1544: 358-369.

Yang Q, Nagano T, Shah Y, Cheung C, Ito S, Gonzalez FJ. 2008. The PPAR alpha-humanized mouse: a model to investigate species differences in liver toxicity mediated by PPAR alpha. Toxicol. Sci. 101: 132-139.

Yeldandi AV, Rao MS, Reddy JK. 2000. Hydrogen peroxide generation in peroxisome proliferator-induced oncogenesis. Mutat. Res. 448 : 159-177. 